- Restorations placed within the NHS regulations were replaced at a significantly lower age than restorations placed under the other funding arrangements investigated

- There may be many reasons for this finding, including patient factors, such as poorer oral hygiene for NHS patients than private patients, or different dentist attitudes

- The most prevalent reason for replacement of restorations was secondary caries. The funding of the restoration had no influence on this

- Composite materials were more frequently used within the private and private/capitation arrangements

- The practitioners involved in the study felt that the data were easy to collect, and further studies of this type would appear appropriate

\title{
Influence of the method of funding on the age of failed restorations in general dental practice in the UK
}

\author{
F. J. T. Burke, ${ }^{1}$ N. H. F. Wilson, ${ }_{1}^{2}$ S. W.Cheung ${ }^{3}$ and I. A. Mjör ${ }^{4}$
}

Objective: This study examined the effect of the method of funding treatment on the age of restorations at the time of replacement. Method: A group of general dental practitioners were recruited to take part in the study. Each participant was asked to record the reason for placement and replacement of restorations. The age and class of the restoration being replaced was also recorded, together with details of the material being used and the material being replaced. Details of the method of payment of the failed restoration were recorded.

Results: Details of the reason for placement/replacement were received for 3,196 restorations from 32 GDPs. Of the restorations placed, 54\% were amalgam, 32\% composite, $8 \%$ compomer and $7 \%$ glass ionomer. The age of restorations at the time of replacement was significantly associated with the method of payment for the restoration, with restorations placed in the Armed Forces having been in service significantly longer at the time of their replacement than restorations placed under NHS regulations.

Conclusion: Statistical analysis indicated that restorations placed within the NHS regulations were replaced at a significantly lower age than restorations placed under the other funding arrangements investigated.

The provision of long-lasting restorations is central to success in general dental practice, given that the effective restoration of teeth fosters patient confidence - in the practitioner and ultimately, the profession - and, in turn, delays the removal of restorations, which invariably leads to a further loss of tooth tissue, let alone being a costly experience for the patient. The longevity of restorations may be dependent upon many factors, including the age of the patient, the clinician's gender, ${ }^{1}$ operator skill, the materials and techniques used, patient compliance with oral hygiene advice, caries susceptibility and, possibly, the means by which the treat-

\footnotetext{
$1^{*}$ Professor of Primary Dental Care, ${ }^{3}$ Research Assistant, University of Birmingham School of Dentistry, St.Chad's Queensway, Birmingham B4 6NN; ${ }^{2}$ Professor of Restorative

Dentistry, University Dental Hospital of Manchester, Higher Cambridge Street, Manchester M15 6FH; Present position: Dean \& Head of School, GKT Dental Institute, University of London: ${ }^{4}$ Professor, Department of Operative Dentistry, University of Florida College of Dentistry, Health Science Center, P.O. Box 100415, Gainesville, Florida, FL 32610-0415, USA ${ }^{*}$ Correspondence to : Prof F. J. T. Burke

E-mail:f.j.t.burke@bham.ac.uk
}

\section{Refereed paper}

Received 05.05.00; Accepted 15.01.02

( ) British Dental Journal 2002; 192: 699-702 ment is funded. ${ }^{2}$ There are few investigations on the effect of these factors on restoration longevity. In particular, there is a paucity of information on the influence of the method whereby the failed restoration was funded (for example, by salaried clinicians or private practitioners to whom patients pay a fee per item of treatment) on reasons for replacement of restorations and on restoration age at replacement. ${ }^{2}$

Another paper has investigated the influence of patient factors such as oral hygiene status and caries susceptibility on age at which restorations are replaced. ${ }^{2}$ The purpose of this study was to extend the work already reported ${ }^{2}$ to examine the effect of method of payment for the failed restoration on the age at which restorations are replaced.

\section{METHOD}

The method of data collection has previously been described in detail. ${ }^{3,4}$ For the present study, participants were recruited from a group of general dental practitioners who were interested in carrying out practice-based research (GRID: Glasgow Research Initiative in Dental Practice) and by advertising in the newsletter of the Faculty of General Dental Practitioners (UK). All participants were sent an introductory letter and an instruction sheet, including a laminated card describing the various reasons for the placement and the replacement of restorations. This list has previously been published by Burke and co-workers ${ }^{4}$ and Mjör and Moorhead. ${ }^{5}$ Each participant was asked to record the reason for the placement or the replacement of consecutive restorations placed in their practice during March 1999. By examination of the patient's retrospective records, the participants were also asked to record the following:

1. Data on each restoration replaced, the age of the failed restoration, the type of restoration by class, the material of the initial restoration and the material selected for the replacement restoration, ${ }^{2}$ and

2. The contractual arrangements (ie method of payment) according to the definitions given in Table 1 under which the restoration was placed, if this information was available from the patient's records.

Patient details, including gender, age, oral hygiene, caries susceptibility and occlusal function were also recorded. A form was designed to enable participants to quickly and easily record the information required. One hundred copies of this form were dis- 
tributed to each participant with instructions in their use. In situations where more than one reason for replacement was possible, participants were asked to record the principal reason for intervention. The data collected were computerised and analysed using the statistical package SPSS for Windows 6.1.3. Basic descriptive statistics including cross-tabulation tables were produced, and, where appropriate, non-parametric tests such as Mann-Whitney $U$ test and Kruskal-Wallis tests were performed. Multivariate statistical analysis by analysis of covariance (ANCOVA) was also performed.

\section{RESULTS}

\section{General data}

Thirty-two general dental practitioners participated. A majority worked under National Health Service (NHS) regulations, but all except those who worked for the Armed Forces provided treatment under more than one method of funding, for example, providing some restorations under private arrangements and others within the NHS. Data were provided on a total of 3,196 restorations, of which 1,097 (34\%) were initial placements. The remaining 2,099 restorations were replacements. Overall, $53.5 \%$ of the restorations placed were amalgam $(n=1,710), 31.5 \%$ composite $(n=1,008)$, $8.2 \%$ were compomer $(n=265)$ and $6.7 \%$ glass ionomer $(n=213)$. The most prevalent reason for replacement of restorations was secondary caries. Analysis of the data has indicated that there was no significant difference in the likelihood of a restoration failing as a consequence of secondary caries between the four methods of funding investigated.

\begin{tabular}{ll} 
Table 1 Instructions for recording patient data \\
Contractual arrangements & $\begin{array}{l}\text { Give details for the arrangements for payment of } \\
\text { the restoration. These may be Armed Forces, } \\
\text { private contract between patient and dentist, an } \\
\text { insurance or private capitation scheme such as } \\
\text { Denplan, and, finally, NHS. }\end{array}$ \\
\hline $\begin{array}{l}\text { Is based, if possible, on your opinion of the overall } \\
\text { adequacy of the patient's oral hygiene during the } \\
\text { previous } 5 \text { years if this can be gleaned from the } \\
\text { patient's records. If records are not available, } \\
\text { please base your rating on the adequacy of oral } \\
\text { hygiene at the visit when the restoration is being } \\
\text { replaced. }\end{array}$ \\
$\begin{array}{l}\text { Is based, if possible, on your opinion of the } \\
\text { patient's caries activity over the previous } 5 \text { years if } \\
\text { this can be gleaned from the patient's records. If } \\
\text { records are not available, please base this on the } \\
\text { amount of untreated caries identified at start of } \\
\text { the patient's present course of treatment. }\end{array}$ \\
$\begin{array}{l}\text { Excessive or normal. } \\
\text { Excessive occlusal function may be considered to } \\
\text { be abnormal occlusal function which has resulted } \\
\text { in excess wear for the age of the patient. }\end{array}$ \\
\hline Occlusal function
\end{tabular}

It was possible to determine the previous restorative material from the patient's records for 1,937 of the replacement restorations (amalgam 1,288, composite 451, glass ionomer 142, compomer 41, gold 8 and silicate 7), allowing historical details of the restoration, including method of funding, to be retrospectively analysed.

The mean age of the patients was 41.4 years.

\section{Influence of contractual arrangements}

The contractual arrangements under which the failed restorations were provided are shown in Table 2. Table 3 shows the mean age of the different types of restoration at failure. Analysis of the data enabled restoration age at failure, according to type of material, to be compared with contractual arrangements for funding the restoration. When restoration age at failure was compared with the funding arrangements under which the restoration was placed, the results

\begin{tabular}{lcc}
\multicolumn{3}{l}{ Table 2 Contractual arrangements under which restorations were provided } \\
\hline & Number & Percentage \\
\hline National Health Service & 2,082 & 65.2 \\
Private & 604 & 18.9 \\
Private/Insurance & 307 & 9.6 \\
Armed Forces & 202 & 6.3 \\
Unrecorded & 1 & \\
Total & 3,196 & 100
\end{tabular}

\begin{tabular}{|c|c|c|c|c|}
\hline Material & $\begin{array}{l}\text { Age at Failure } \\
\text { Private }\end{array}$ & $\begin{array}{c}\text { Age at Failure } \\
\text { Private/Insurance }\end{array}$ & $\begin{array}{c}\text { Age at Failure } \\
\text { NHS }\end{array}$ & $\begin{array}{l}\text { Age at Failure } \\
\text { Armed Forces }\end{array}$ \\
\hline Overall & 8.7 (7) & $8.1 \quad$ (7) & $5.9 \quad(5)$ & $10.3(8.5)$ \\
\hline Amalgam & $10.3(8)$ & $9.0 \quad(8)$ & $7.0 \quad(6)$ & $10.6(10)$ \\
\hline Composite & $7.4(4)$ & $6.4 \quad(6)$ & $4.7 \quad(4)$ & $7.8 \quad$ (7) \\
\hline Glass lonomer & $3.9(3)$ & $6.7(6.5)$ & $3.1(2.5)$ & - \\
\hline
\end{tabular}

indicated that, overall, there was a highly significant difference between the four methods of funding and age of restoration at replacement, with restorations placed under the NHS having a lower age at failure than restorations placed under other arrangements, this being statistically significant using a Kruskal-Wallis one-way analysis of variance (chi-square value $=75.351, P<0.0001$ ). Restorations placed under the Armed Forces arrangements had the greatest age at failure. There were no data on glass ionomer or compomer restorations having been replaced under the Armed Forces arrangements as these materials have only recently been introduced into the Armed Forces Dental Service.

Statistical analysis of the results for the individual restorative materials using a Kruskal-Wallis one-way analysis of variance indicated that the NHS restorations had a significantly reduced age at failure in comparison with the restorations placed under other contractual arrangements (chi-square value $=35.5$ for amalgam, 14.0 for composite and 16.3 for glass ionomer, $P<0.0001$ ). When the data were analysed using ANCOVA, method of funding was found to be highly statistically significant to the age of restoration at the $0.1 \%$ level ( $F$ statistics $=17.85,6$ degree of freedom) after controlling the covariates. Patient oral hygiene and occlusal function are statistically significant at the 5\% level (F statistics 8.1 and $6.25,1$ degree of freedom respectively) and the effect of caries susceptibility has disappeared. When one-way analysis of variance is perfomed on the data to test overall age of restoration against funding methods, restorations placed within the NHS tended to have a lower age at replacement than other contractual methods of funding restorations.

The compomer restorations were not analysed as these materials have been in use for a much shorter period than the other materials assessed and the results for these would therefore not bear comparison.

\section{Materials used vs contractual arrangements}

The materials used in the different systems for funding are shown in Table 4. Higher percentages of amalgam restorations were placed in the Armed Forces and under the NHS arrangements than in Private or Private/Capitation arrangements. Composite materials were more frequently used within the Private and Private/Capitation arrangements. Compomer materials were not used within the Armed Forces at the time of the study.

When ANCOVA was carried out, age of restoration for amalgam was found to be highly statistically significant between the con- 


\begin{tabular}{|c|c|c|c|c|}
\hline $\begin{array}{l}\text { Contractual } \\
\text { Arrangement }\end{array}$ & $\begin{array}{c}\text { Amalgam } \\
\% \text { placed } \\
(n=1,710)\end{array}$ & $\begin{array}{c}\text { Composite } \\
\% \text { placed } \\
(n=1,007)\end{array}$ & $\begin{array}{c}\text { Glass I } \\
\% \text { placed } \\
(n=213)\end{array}$ & $\begin{array}{l}\text { Compomer } \\
(n=265)\end{array}$ \\
\hline Private & 42.7 & 40.7 & 6.6 & 9.9 \\
\hline P/Insurance & 51.8 & 39.1 & 5.2 & 3.9 \\
\hline NHS & 55.6 & 28.2 & 7.0 & 9.3 \\
\hline Armed Forces & 67.3 & 26.7 & 5.9 & 0.0 \\
\hline
\end{tabular}

tracts at the $0.1 \%$ level ( $\mathrm{F}$ statistics $=12.18,6$ degree of freedom, $P<0.0001)$. However, covariate oral hygiene is still significant at the $0.1 \%$ level.

With regard to composite restorations, age of restoration was found to be highly statistically significant between the contracts at the $0.1 \%$ level (F statistics $=3.76,6$ degree of freedom, $P<0.0001$ ). However, covariate occlusal function is at borderline of significance at the $0.1 \%$ level.

With regard to glass ionomer restorations, age of restoration was found to be highly statistically significant between the contracts at the $0.1 \%$ level ( $\mathrm{F}$ statistics $=6.98,5$ degree of freedom, $P<0.0001)$. However, covariate occlusal function was at borderline of significance at the $0.1 \%$ level.

\section{Age of patient vs contractual arrangements}

A Kruskal-Wallis ANOVA indicated a highly significant difference between patient's age and method of funding of restorations $(P<0.0001)$. The mean rank indicates that older patients tended to receive their treatment under private/insurance, followed by private contract, while patients in the younger age groups tended to be in the Armed Forces or treated under the NHS.

\section{Age of patient vs age of restoration at replacement}

When amalgam restorations were assessed with regard to age of restoration vs patients' age, there was a highly significant relationship between the two variables (chi-square $=59.04,4$ degree of freedom, $P<0.0001$ ), with the younger patient age groups having a reduced age of restoration at failure than older age groups. For composite restorations, glass ionomer restorations and compomer restorations, no significant association was noted between patient age and age of restoration at replacement.

\section{Caries susceptibility vs contractual arrangements}

These data are shown in Table 5. A highly significant difference was noted between caries susceptibility and the four different methods of funding treatment $(P<0.0001)$. With regard to caries susceptibility, the results indicated that, of the 828 patients rated as having high caries susceptibility, 30.7\% of NHS patients were rated as having high caries susceptibility, as compared with $20.9 \%$ of private patients, 15.8\% of armed forces patients and 9.8\% of private/insurance patients. The differences in relation to moderate and low caries susceptibility patients are less notable, except for the higher proportion of low caries susceptibility patients in the private/insurance group.

\begin{tabular}{|c|c|c|c|c|c|}
\hline \multirow{2}{*}{$\begin{array}{l}\text { Caries } \\
\text { susceptibility }\end{array}$} & \multicolumn{3}{|c|}{ Method of funding } & & \multirow[t]{2}{*}{$\%$ of total } \\
\hline & Private & Private/Insurance & NHS & Armed Forces & \\
\hline High & 20.9 & 9.8 & 30.7 & 15.8 & 25.9 \\
\hline Moderate & 30.5 & 32.6 & 35.7 & 36.6 & 34.5 \\
\hline Low & 48.6 & 57.7 & 33.6 & 47.5 & 39.6 \\
\hline
\end{tabular}

\section{Oral hygiene vs contractual arrangements}

These data are shown in Table 6. A high correlation was noted at the $0.01 \%$ level between oral hygiene and the four different methods of funding of treatment $(P<0.0001)$. The results indicate that, of the 1,166 patients rated as having good oral hygiene, 55.7\% of the private/insurance patients were rated as having good oral hygiene, compared with $44.1 \%$ of Armed Forces patients, 38.0\% of private patients and $32.5 \%$ of NHS patients.

\begin{tabular}{|c|c|c|c|c|c|}
\hline \multirow[t]{2}{*}{ Oral hygiene } & \multicolumn{4}{|c|}{ Method of funding } & \multirow[t]{2}{*}{$\%$ of tota } \\
\hline & Private & Private/Insurance & NHS & Armed Forces & \\
\hline Good & 38.0 & 55.7 & 32.5 & 44.1 & 36.5 \\
\hline Fair & 37.5 & 31.9 & 47.9 & 43.6 & 44.2 \\
\hline Poor & 24.4 & 12.4 & 19.5 & 12.4 & 19.3 \\
\hline
\end{tabular}

\section{DISCUSSION}

This study has examined the influence of the method of payment of the provision of restorations as a function of restoration age at the time of replacement and the reasons why restorations are replaced. The data presented relates to the age at which restorations were replaced and should not be confused with data on restoration longevity, although the two are connected.

The methods used in this project were derived from previous projects, ${ }^{2,3,5}$ with the data collection forms being redesigned to allow collection of additional information on the method of funding of treatment. These are 'real life' data from general dental practice, in which the dental health of the UK is principally placed. Although the participants had little experience in the recording of data for research reasons, the data analysed is largely 'historical' and was obtained by examination of the patients' records. The data presented in this project represents data from a selected group of patients, namely, regularly attending patients, given that it is only this group who will have historical details of restorations previously placed. The data may therefore represent a 'best possible' scenario for restoration age at replacement given that it is obtained from the records of regularly attending patients. These patients may be likely, by inference, to have a concomitant interest in their oral health by seeking dental care on a regular basis. It is also likely that restorations are replaced less frequently if patients attend the same dentist year after year. ${ }^{6}$

The GDPs participating in the project may not be representative of GDPs as a whole, since the whole range of GDPs will not actively participate in research projects such as this. The numbers of GDPs participating in the study, although relatively small, may be considered sufficient for the intended purpose of the investigation, but is also a reflection of the difficulty in recruiting GDPs who are prepared to collect data such as those required. Nevertheless, the volume of data collected is considered sufficient to allow comparison between patients treated under different methods of funding. With regard to the data collected on the restorations in the private/capitation group, these may be considered to be disadvantaged as compared with the other funding schemes, given that the first UK-based private capitation scheme, Denplan, was started in 1987. Restorations from this group have therefore a maximum age of 12 years at the time of the study.

Regarding the age of the failed restorations, analysis of the data from the present study has indicated that restorations placed under private contract, private insurance schemes and in the Armed Forces were found to perform significantly better in terms of age at replacement than restorations placed under the NHS regulations. Furthermore, the restorations placed under private contract, private insurance and in the Armed Forces compared favourably in 
terms of age at time of failure with those in other countries, while the restorations placed within the NHS regulations do not. ${ }^{7-10}$ The reasons for this discrepancy are by no means straightforward but the following may be offered as possibilities:

- The restorations placed outside the NHS may be of higher quality and are thereby more durable. However, the situation is unlikely to be as straightforward as this.

- A person working in an item-of-service scheme (ie NHS or fully private) might be more inclined to replace a given restoration than someone working in a capitation scheme.

- There may be differences in the patient groups, between NHS, private and Armed Forces, in terms of social status. It has been recognised that caries is less prevalent amongst patients in higher social groups. ${ }^{11}$ It appears from the data in the present study that patients receiving treatment within the NHS Regulations have poorer oral hygiene and higher caries susceptibility than patients who receive their dentistry under private contract. This may be another manifestation of patients from different social groups being treated under different methods of funding. Attendance patterns may be different for different groups, but this was not examined in the present study. Furthermore, patients who pay less for treatment may value their treatment less than those who pay private fees. They are therefore less likely to achieve optimum levels of maintenance. ${ }^{12}$

- The difference in mean age of restorations at the time of replacement between the NHS and the other forms of remuneration may be the result of differences in dentists' attitudes rather than different patient values. It may be that dentists operating within the NHS Regulations may be using different, outmoded, criteria for assessment of restorations, a factor which has previously been suggested as a reason for differences in dentists' attitudes. ${ }^{13}$ It may be that the dentists whose restorations provide least longevity are not aware of the research that demonstrated little correlation between marginal defects around restorations and secondary caries until the marginal gap is at least $0.4 \mathrm{~mm} .{ }^{14}$ It may also be that the NHS dentist finds it necessary to place restorations in less time than the private dentist, who may be charging three times the fee per item of work, ${ }^{15}$ but also spending a longer time carrying out the treatment. In this respect, there is evidence that dentists within the Armed Forces see fewer patients per session than many dentists working within the NHS arrangements (I. McIntyre, personal communication, 1999). This may lead to improved placement of restorations, for example, improved condensation of amalgam restorations and better awareness of moisture control.

In the Armed Forces, patients transport their own dental records whenever they are posted to a new location. It therefore follows that Armed Forces personnel may be treated by a series of different dentists, this, in itself being a form of peer review, which may be considered to enhance quality (M. Sherlock, personal communication, March 2001).

- Finally, the differences in restoration age at replacement among the different methods of payment may also reflect differences in postgraduate attendance and consequent levels of knowledge. Attendance at postgraduate education courses is compulsory for members of the Armed Forces. This may, in turn, lead to improved standards of clinical care.
It would therefore seem important, and timely, to compare the fees paid by patients, and the taxpayers' payment for exempt patients, and the time taken for treatment under the different systems investigated and to compare the findings with the age of restorations when their replacement is deemed necessary. By this means the cost effectiveness of restorations placed under the different systems could be assessed. It is clear that the fees paid in the private system are higher than those in the NHS, but the greater age at failure of the non-NHS restoration may balance the higher cost in terms of patient payments (under the private and private/capitation systems) or reduced numbers of patients treated (for example, within the Armed Forces dental service).

The provision of accessible, affordable and acceptable dental care is central to general dental practice. It remains to be seen whether the results from this study indicate that the NHS General Dental Services are sacrificing acceptability at the cost of affordability, let alone the loss of tooth tissue which occurs during restoration replacement, and also, currently, at the cost of accessibility in many parts of the UK.

\section{CONCLUSION}

The results indicate that restorations placed within the NHS regulations were replaced at a significantly lower age than restorations placed under the other funding arrangements investigated.

The authors wish to thank the participating dentists for their diligence and time in completing the data collection forms: the project could not have been carried out without their help. The views expressed in this paper are those of the authors and do not reflect the views and policy of other organisations with which they are associated

1. Mjör I A, Dahl J E, Moorhead J E. The age of restorations at replacement in permanent teeth in general dental practice. Acta Odontol Scand 2000; 58: 97-101.

2. Burke F J T, Cheung S W, Mjör I A, Wilson N H F. Influence of patient factors on age of restorations at failure and reasons for placement and replacement of restorations by a group of general dental practitioners. J Dent 2001: 29: 317-324.

3. Wilson N H F, Burke F J T, Mjör I A. Reasons for placement and replacement of restorations of direct restorative materials by a selected group of practitioners in the United Kingdom. Ouintessence Int 1997: 28: 245-248.

4. Burke F JT, Cheung S W, Mjör I A., Wilson N H F. Restoration longevity and analysis of reasons for the placement and replacement of restorations provided by vocational dental practitioners and their trainers in the United Kingdom. Quintessence Int 1999, 30: $234-242$

5. Mjör I A, Moorhead J E. Selection of restorative materials, reasons for replacement and longevity of restorations in Florida. J Amer Coll Dent 998; 45: 27-33.

6. Dawson A S, Makinson O F. Dental treatment and dental health. Part 1. A review of studies in support of a philosophy of minimal intervention dentistry. Aust Dent J 1992; 372: 126-132.

7. Mjör | A, Toffenetti F. Placement and replacement of amalgam restorations in Italy. Oper Dent 1992; 17: 70-73.

8. Fried K-H, Hiller K A, Schmaltz G. Placement and replacement of amalgam restorations in Germany. Oper Dent 1994; 19: 228-232.

9. Mjör | A. The reason for replacement and the age of failed restorations in general dental practice. Acta Odontol Scand 1997; 55: 58-63.

10. Smales R J, Hawthorne W S. Long-term survival of extensive amalgams and posterior crowns. J Dent 1997; 25: 225-227.

11. Todd J E, Lader D. Adult Dental Health Report, 1988. London, Her Majesty's Stationery Office, 1990.

12. Brown A D, Mellor A C, Main J R. A survey of patient perceptions of dental charges. Primary Dent Care 1999; 6: 151-155.

13. Report of the Committee of Enquiry into Unnecessary Dental Treatment. 1986, London, Her Majesty's Stationery Office.

14. Kidd E A M, Joyston-Bechal S, Beighton D. Marginal ditching and staining as a predictor of secondary caries around amalgam restorations: A clinical and microbiological study. J Dent Res 1995; 74: 1206-1211.

15. UK Dental Care Market Sector Report 1999. 1999, London: Laing and Buisson. 